\title{
A modification of the clip-flap technique: the clip-band-flap technique
}

The clip-flap technique was described to facilitate creating a mucosal flap at the beginning of colorectal endoscopic submucosal dissection (ESD) [1-4]. The creation of the mucosal flap is a critical step in colorectal ESD, with a high risk of perforation especially for beginners. The clip-band technique has been used in gastric and colorectal ESD. The second clip is used to clamp the band, and it is attached to the normal mucosa distal or opposite to the resection site after the circumferential incision is complete [5] ( Fig. 1).

However, the first clip and the band (not only the clip) could be applied using the clip-flap technique to help create a mucosal flap, and then at some point the second clip could be applied at the discretion of the endoscopist.

In this case, a nongranular pseudodepressed laterally spreading tumor (LST) in the ascending colon was assessed with narrow-band imaging (NBI) magnification, classified as type $2 \mathrm{~B}$ per the Japan NBI Expert Team, and treated by ESD with an SB Junior knife (Sumitomo Bakelite Co., Ltd., Tokyo, Japan). The clip-band-flap technique was applied. By pushing the endoscope and cap against the base of the clip, the submucosal layer became exposed. Later, the second clip was applied after the circumferential incision was
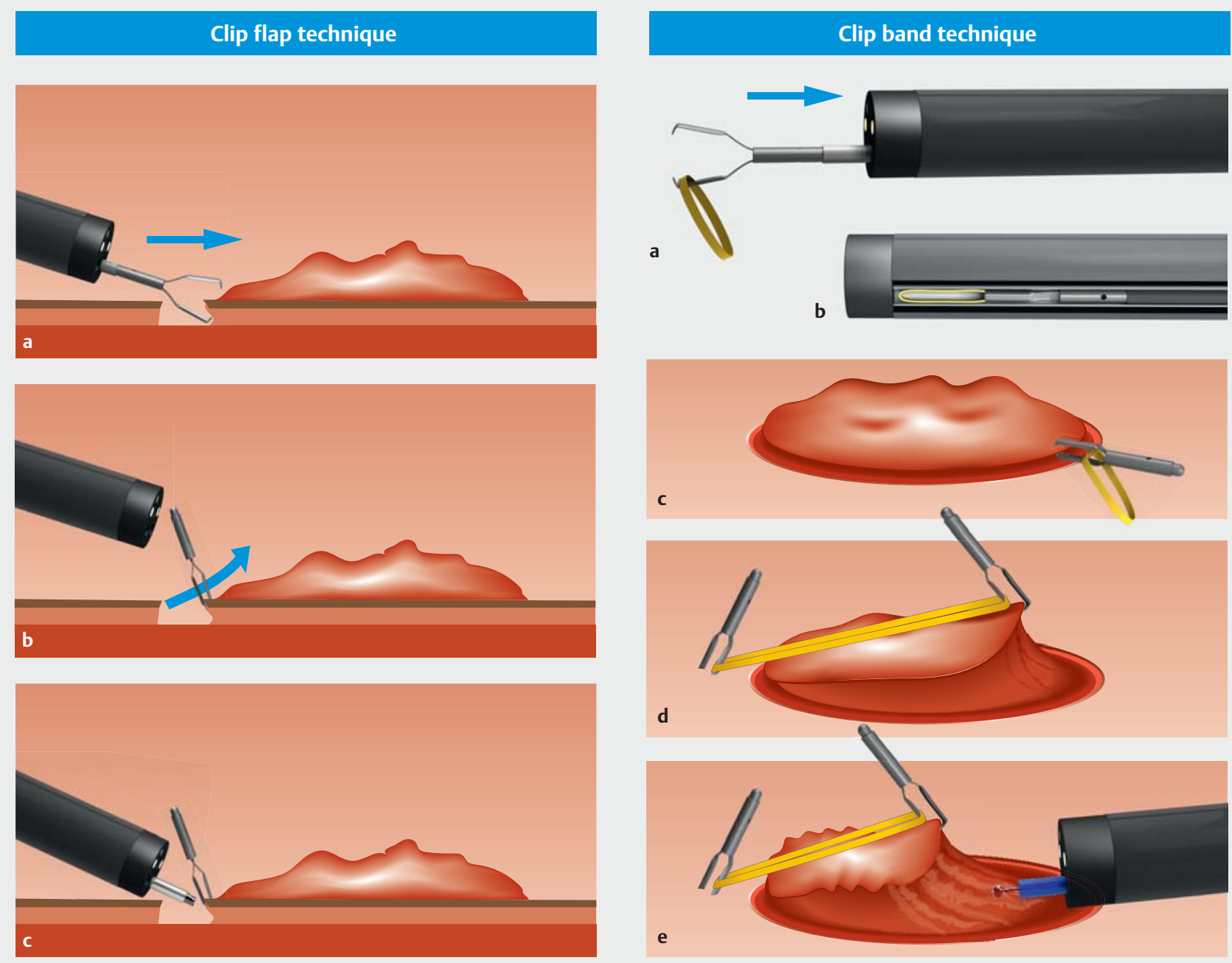

Fig. 1 Clip-flap technique. a A clip is placed in the edge of the target mucosa. b, $\mathbf{c}$ The endoscope with distal attachment is slipped under the endoclip, facilitating submucosal access and creating the mucosal flap. Clip-band technique. a, b, $\mathbf{c}$ The clip-band is applied in the inner margin of the resected mucosa. $\mathbf{d}$, e The second clip is attached to the normal distal mucosa, exerting traction and facilitating submucosal layer visualization during dissection. 


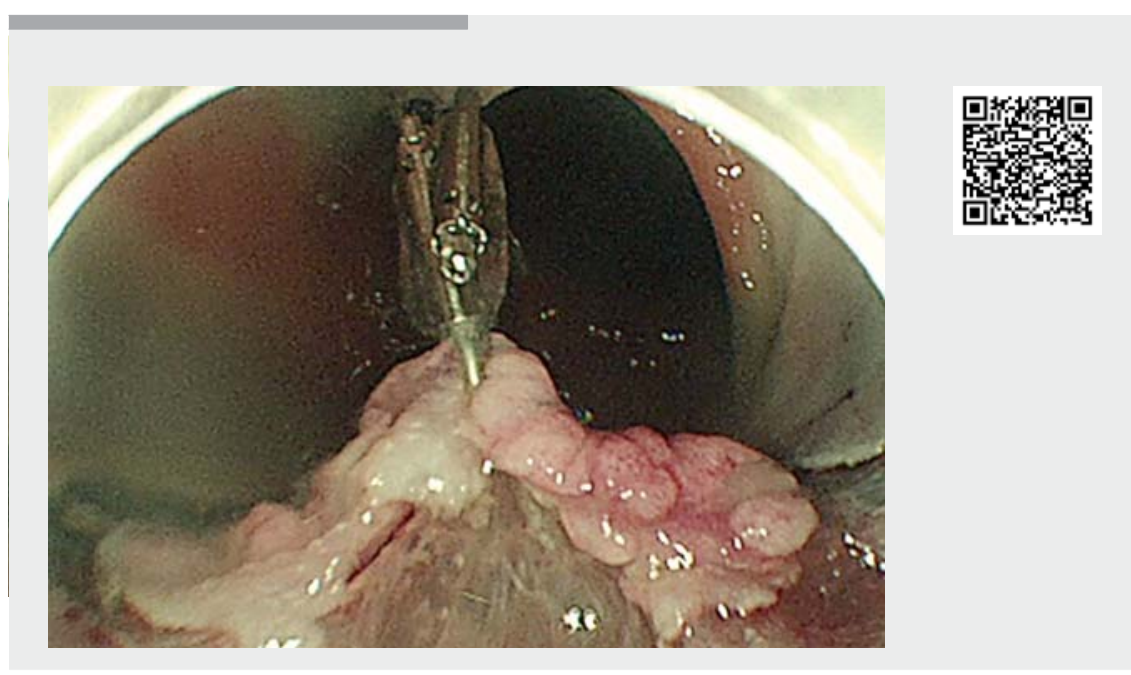

Video 1 "Clip-flap-band technique" is applied at the beginning of the endoscopic submucosal dissection, facilitating initial access to the submucosa. To facilitate dissection, the initial positioning of the band is used later to apply traction using the clip-band.

completed. For placement of the second clip, we always perform a submucosal injection with dye in the target area to prevent any injuries to the muscle layer when the second clip is pulled and detached with a snare. The dissection was completed uneventfully. Histology showed slight submucosal invasion $(900 \mu \mathrm{m})$ with no high risk factors, although the distance to the vertical margin was only $100 \mu \mathrm{m}$ ( $\vee$ Video 1$)$

In summary, we propose a slight and simple modification of the clip-flap technique by also applying a band. In this way, two-stage traction can be applied in a sequential fashion.

Endoscopy_UCTN_Code_TTT_1AQ_2AJ

\section{Competing interests}

The authors declare they have no conflict of interest.

\section{References}

[1] Yamamoto K, Hayashi S, Nakabori T et al. Endoscopic submucosal dissection using endoclips to assist in mucosal flap formation (novel technique: "clip flap method"). Endoscopy 2012; 44 (Suppl. 02): E334-E335

[2] Yamamoto K, Hayashi S, Saiki H et al. Endoscopic submucosal dissection for large superficial colorectal tumors using the "clipflap method". Endoscopy 2015; 47: 262265

[3] Yamamoto K, Hayashi S, Nishida T et al. Effective use of the "clip-flap" method for the endoscopic submucosal dissection of a difficult-to-approach superficial gastric tumor. Endoscopy 2015; 47 (Suppl. 01): E318-E319

[4] Yamamoto K, Michida T, Nishida T et al. Colorectal endoscopic submucosal dissection: recent technical advances for safe and successful procedures. World J Gastrointest Endosc 2015; 7: 1114-1128

[5] Parra-Blanco A, Nicolas D, Arnau MR et al. Gastric endoscopic submucosal dissection assisted by a new traction method: the clipband technique. A feasibility study in a porcine model (with video). Gastrointest Endosc 2011; 74: 1137-1141

Adolfo Parra-Blanco', Miguel Fraile-López ${ }^{1,2}$

1 NIHR Nottingham Biomedical Research Centre, Department of Gastroenterology, Nottingham University Hospitals NHS Trust and University of Nottingham, Nottingham, UK

2 Department of Gastroenterology, Hospital Universitario Central de Asturias, Oviedo, Spain

\section{Corresponding author}

\section{Adolfo Parra-Blanco, MD}

Nottingham City Hospital Campus, Nottingham University Hospitals NHS Trust, Hucknall Rd., Nottingham NG5 1PB, United Kingdom

Fax: +44-115-8405821

Adolfo.Parra-Blanco@nottingham.ac.uk techniques in gastroenterological endoscopy. All papers include a high quality video and all contributions are freely accessible online.

This section has its own submission website at https://mc.manuscriptcentral.com/e-videos 